\title{
CLOROFILA NA FOLHA COMO INDICADOR DO NÍVEL DE NITROGÊNIO EM CEREAIS
}

\author{
LEAF CHLOROPHYLL AS AN INDEX OF NITROGEN STATUS \\ IN CEREALS
}

Gilber Argenta $^{1}$ Paulo Regis Ferreira da Silva $^{2}$ Clayton Giani Bortolini ${ }^{3}$

-REVISÃO BIBLIOGRÁFICA-

RESUMO

O desenvolvimento recente do medidor portátil de clorofila, que faz leituras instantâneas sem necessidade de destruição da folha, surge como nova ferramenta para avaliar o nível de $N$ na planta. As leituras efetuadas por este equipamento indicam valores proporcionais de clorofila na folha e são calculadas com base na quantidade de luz transmitida pela folha em dois comprimentos de ondas com distintas absorbâncias de clorofila. Nas culturas de arroz, trigo, aveia e milho, foram evidenciadas boas correlações entre leitura SPAD e rendimento de grãos. Os níveis críticos de leitura no medidor portátil de clorofila, correspondentes ao nível adequado de $\mathrm{N}$, determinados nas culturas de arroz (diferenciação da panícula), trigo (folha bandeira) e milho (espigamento) são de, respectivamente, 40-42, 41-42 e 58-62. No entanto, por se tratar de uma técnica nova, apresenta limitações, tais como: pouca amplitude entre as leituras, influência sobre as leituras de outros fatores além do $\mathrm{N}$ e, especificamente para o milho, apresentação de baixa correlação com rendimento de grãos nos estádios iniciais de desenvolvimento da planta. Estas limitações estão sendo corrigidas ou minimizadas através da utilização de fatores de correção como o uso de faixa de referência, o peso específico da folha, a área foliar e de massa seca da planta. Apesar das limitações apresentadas, a utilização do parâmetro teor de clorofila da folha apresenta grande potencial como indicador para a recomendação de adubação nitrogenada em cereais, principalmente se associado a indicadores de solo.
Palavras-chave: Zea mays, Triticum aestivum, Oryza sativa,
Avena sp., adubação nitrogenada, clorofilometro.

\section{SUMMARY}

The development of a portable chlorophyll meter, which allows instantaneous measurement without leaf destruction, has been used as a new tool to assess plant $N$ status. The reading in the equipment indicates a relationship with leaf chlorophyll and they are calculated based on the emission of light quantity through of the leaf in two wavelengths with different chlorophyll absorbance. Some researchers have established association between SPAD reading and chlorophyll content and between chlorophyll content and plant $N$ content. In rice, wheat, oat and maize there were determined good associations between $S P A D$ reading and grain yield. The critical level of a portable chlorophyll meter, correspondent with adequated $N$ level, determined in rice (panicle differentiation), wheat (leaf flag) and maize (silking) are of, respectively, 40-42, 41-42 and 58-62. However, since it is a new tool, this equipment presents some limitations such as: little variation between readings, the readings are influenced by other factors besides $N$ and, especifically for maize, to present low correlation with grain yield in the initial stages of plant development. These limitations were be to solve or minimize through the utilization of correction factores such as the use of strip reference, specific leaf weight, leaf area and plant dry matter. Despite of the limitations presented, the use of the leaf chlorophyll content shows high

\footnotetext{
${ }^{1}$ Engenheiro Agrônomo, MSc, Estudante de Doutorado do Curso de Pós-graduação em Fitotecnia, Faculdade de Agronomia da Universidade Federal do Rio Grande do Sul (UFRGS). Bolsista do CNPq. Av. Bento Gonçalves, 7712, CP 776, 91540-000, Porto Alegre, RS. E-mail: plantas@vortex.ufrgs.br. Autor para correspondência.

${ }^{2}$ Engenheiro Agrônomo, PhD, Professor Adjunto do Departamento de Plantas de Lavoura, Faculdade de Agronomia, UFRGS. Pesquisador do CNPq.

${ }^{3}$ Engenheiro Agrônomo, Estudante de Mestrado do Curso de Pós-graduação em Fitotecnia, Faculdade de Agronomia, UFRGS. Bolsista da CAPES.
} 
potential as an indicator for nitrogen fertilization recommendation in cereals, especially if associate as soil indicators.

Key words: Zea mays, Triticum aestivum, Oryza sativa, Avena sp., nitrogen fertilizer, chorophyll meter.

\section{INTRODUÇÃO}

Nos cereais, a adubação nitrogenada é baseada na recomendação da COMISSÃO... (1995). $\mathrm{Na}$ cultura do arroz irrigado, os critérios levados em consideração são o teor de matéria orgânica do solo e a estatura de planta das cultivares. Nas culturas da aveia, cevada, sorgo e triticale, a adubação baseia-se apenas no teor de matéria orgânica. Nas culturas de milho e trigo a recomendação leva em consideração, além do teor de matéria orgânica, a expectativa de rendimento de grãos. $\mathrm{Na}$ agricultura de precisão, que objetiva a aplicação localizada e nas quantidades requeridas de insumos agrícolas, a adoção de apenas estes critérios é insuficiente. Portanto, o uso de outros parâmetros, como o teor de clorofila na folha, pode tornar-se importante ferramenta para aumentar a precisão no processo de recomendação de adubação nitrogenada em cereais.

Alguns modelos matemáticos foram desenvolvidos com o objetivo de monitorar o crescimento e o desenvolvimento das plantas nos cereais (SINCLAIR \& MUCHOW, 1995). No entanto, a aplicação desses modelos em nível de lavoura é dificultada pelo fato de parâmetros climáticos determinantes do crescimento da planta e da disponibilidade de $\mathrm{N}$ no solo serem imprevisíveis e pelo pouco conhecimento disponível sobre os mecanismos básicos que governam o ciclo do N (LEMAIRE \& GASTAL, 1997). Tendo presente a ocorrência desta variabilidade e diante da necessidade de se decidir sobre a recomendação, tem-se, em muitos casos, sub ou superestimada a adubação nitrogenada. Assim, quando ela for subestimada tem-se redução no rendimento de grãos e, quando for superestimada, haverá redução nos lucros do agricultor pelo gasto desnecessário com a compra do adubo nitrogenado e prejuízos ao meio ambiente, em função da lixiviação de nitrato devida ao excesso de disponibilidade de $\mathrm{N}$.

A agricultura de precisão, dentre outras finalidades, está sendo proposta como uma nova filosofia de manejo dos cultivos que poderá contribuir para a diminuição da sub ou superutilização de fertilizantes nitrogenados. Trata-se de uma tecnologia de informação que possibilita o gerenciamento da atividade agrícola levando-se em consideração a variabilidade espacial e temporal do solo e da cultu- ra, permitindo desta forma a otimização de recursos do ambiente e o uso racional de insumos agrícolas (FRAISSE, 1998).

Este novo conceito de agricultura pode ser importante na modificação do quadro atual por possibilitar a aplicação localizada de insumos agrícolas no local correto e nas quantidades requeridas. A agricultura de precisão faz uso intenso de tecnologias que foram desenvolvidas fora do contexto tradicional da pesquisa agropecuária, tais como Sistema de Posicionamento por Satélite (GPS/GLONASS), Sistema Geográfico de Informações (GIS/SIG) e Sensoreamento Remoto (FRAISSE, 1998).

Uma abordagem similar, mas que não utiliza estes equipamentos mais sofisticados, pode ser feita através da realização de amostragens pontuais de algum parâmetro de solo e/ou de planta. É neste contexto que o monitoramento do nível de $\mathrm{N}$ em plantas de cereais, através da determinação do teor de clorofila na folha no estádio de desenvolvimento vegetativo, se enquadra na agricultura de precisão.

Alguns métodos de previsão da necessidade de $\mathrm{N}$ durante o período vegetativo dos cereais foram propostos (WILSON et al., 1996; SIMS et al., 1995). Eles baseiam-se em testes de solo e em análises laboratoriais de amostras de plantas. Possuem a vantagem de apresentar boa correlação com rendimento de grãos e de ter aceitável nível de precisão. No entanto, por serem laboratoriais, estes métodos possuem as desvantagens do tempo e trabalho dispendidos e de despesas com coleta, processamento e análise de amostras (WASKOM et al., 1996). Outra restrição a seu uso relaciona-se ao fato de não haver tempo suficiente entre a coleta da amostra e o retorno do resultado da análise laboratorial no mesmo ano agrícola para tomar-se a decisão de se aplicar ou não N. Caso haja atraso da época de aplicação de N, haverá redução no rendimento de grãos.

\section{POTENCIAL DE USO DO TEOR DE CLOROFILA NA FOLHA COMO INDICADOR DO NÍVEL DE N EM CEREAIS}

O desenvolvimento do medidor portátil de clorofila para realização de leituras instantâneas do seu teor na folha, sem haver necessidade de sua destruição, surge como nova ferramenta para avaliação do nível de N nas plantas em cereais (VARVEL et al., 1997; BLACKMER \& SCHEPERS, 1995).

$\mathrm{Na}$ cultura do milho, a relação entre teor de $\mathrm{N}$ na folha e rendimento de grãos já está bem estabelecida (WASKOM et al., 1996). No entanto, o consumo de luxo deste nutriente pela planta sob forma de nitrato, pode resultar em concentração bem 
acima do nível adequado. O teor de clorofila da folha também se correlaciona positivamente com o teor de $\mathrm{N}$ na planta (SCHADCHINA \& DMITRIEVA, 1995) e com o rendimento das culturas (SMEAL \& ZHANG, 1994; PIEKIELEK \& FOX, 1992). Esta relação é atribuída, principalmente, ao fato de que 50 a $70 \%$ do $\mathrm{N}$ total das folhas ser integrante de enzimas (CHAPMAN \& BARRETO, 1997) que estão associadas aos cloroplastos (STOCKING \& ONGUN, 1962).

A vantagem da medição do teor de clorofila é a de não ser influenciada pelo consumo de luxo de $\mathrm{N}$ pela planta, sob forma de nitrato (BLACKMER \& SCHEPERS, 1995). A baixa sensibilidade do medidor de clorofila ao consumo de luxo de $\mathrm{N}$ pelas plantas de cereais é atribuída à forma com que este nutriente se encontra na folha. Quando absorvido em excesso, acumula-se como nitrato. Nesta forma, o $\mathrm{N}$ não se associa à molécula de clorofila e, portanto, não pode ser quantificado pelo medidor de clorofila (DWYER et al., 1995). Por apresentar baixa sensibilidade ao consumo de luxo de $\mathrm{N}$, a medição efetuada pelo medidor de clorofila está sendo considerada melhor indicadora do nível deste nutriente na planta do que o seu teor (BLACKMER \& SCHEPERS, 1995). No entanto, um indicador ideal tem de predizer deficiência e excesso de N (SCHRÖDER $\boldsymbol{e t}$ al., 2000), pois o excesso de $\mathrm{N}$ pode causar danos ao ambiente e aumento no custo de produção.

As leituras efetuadas pelo medidor portátil de clorofila correspondem ao teor relativo de clorofila presente na folha da planta. Os valores são calculados pelo equipamento com base na quantidade de luz transmitida pela folha, em dois comprimentos de ondas, com diferentes absorbâncias da clorofila (MINOLTA, 1989). As regiões de picos de absorbância da clorofila são o azul e o vermelho. As de baixa absorbância situam-se nas regiões do verde e as de absorbância extremamente baixa na região do infravermelho (HENDRY, 1993). Em função disto, os comprimentos de ondas escolhidos para medição do teor de clorofila, ou do índice de esverdeamento, situam-se na faixa do vermelho, em que a absorbância é alta e não é afetada pelos carotenóides, e do infravermelho, em que a absorvância é extremamente baixa.

O medidor de clorofila possui diodos que emitem luz a 650nm (vermelho) e a 940nm (infravermelho). A luz em $650 \mathrm{~nm}$ situa-se próxima dos dois comprimentos primários de ondas associados à atividade da clorofila (645 e 663nm). O comprimento de onda de 940nm serve como referência interna para compensar diferenças na espessura ou no conteúdo de água da folha ou diferenças que se devem a outros fatores (WASKOM, 1996). A luz que passa através da amostra da folha atinge um receptor (fotodiodo de silicone) que converte a luz transmitida em sinais elétricos analógicos. Através do conversor $\mathrm{A} / \mathrm{D}$, estes sinais são amplificados e convertidos em sinais digitais (MINOLTA, 1989) e são usados por um microprocessador para calcular os valores SPAD (Soil Plant Analysis Development), que são mostrados num visor. Os valores obtidos têm relação proporcional ao teor de clorofila presente na folha. Alguns pesquisadores tem demonstrado a existência de relação entre índice de esverdeamento e teor de clorofila na folha em cereais (DWYER et al., 1995; MARQUARD \& TIPTON, 1987).

O medidor portátil de clorofila já foi avaliado em maçã (KAAKEH et al., 1992), algodão (EDMISTEN $\boldsymbol{e t}$ al., 1992), pimentão (HARTZ et al., 1993), tomate (TENGA et al., 1989), sorgo (MARQUARDT \& TIPTON, 1987), arroz (PENG $\boldsymbol{e t}$ al., 1993; TURNER \& JUND, 1991;), trigo (BREDEMEIER, 1999; FOX et al., 1994; REEVES et al., 1993; FOLLET et al., 1992), aveia (BREDEMEIER, 1999) e em milho (ARGENTA $\boldsymbol{e t}$ al., 1999; VARVEL et al., 1997; WASKOM et al., 1996; BLACKMER \& SCHEPERS, 1995; SMEAL \& ZHANG, 1994; PIEKIELEK \& FOX, 1992).

A metodologia utilizada para predizer a necessidade de adubação suplementar de $\mathrm{N}$ em cereais, através do teor de clorofila avaliado em um medidor portátil, baseia-se na criação de variabilidade no início de desenvolvimento das culturas. Geralmente, a variabilidade é gerada pelo emprego de diferentes níveis de $\mathrm{N}$ na semeadura. No estádio em que se deseja determinar os níveis críticos de leitura do clorofilômetro, que são os níveis acima dos quais não é esperada resposta à aplicação de fertilizantes nitrogenados, fazem-se as leituras com o equipamento e aplicam-se de dois a três níveis de N. Com o rendimento de grãos e as leituras SPAD obtidas no estádio desejado determina-se o valor que corresponde ao nível crítico de leitura do clorofilômetro.

Um nível crítico de leitura SPAD tem sido determinado nas diferentes espécies dos cereais. Em arroz, nos estádios de iniciação da pré-panícula e diferenciação da panícula, TURNER \& JUND (1991) determinaram que a leitura SPAD acima da faixa de 40-42 corresponde ao nível crítico de leitura do clorofilômetro (Figura 1). Resultados similares foram obtidos nesta cultura por PENG et al. (1993).

Em trigo, no estádio de Feeke 5, FOX et al. (1994) constataram que a resposta ao fertilizante nitrogenado foi incorretamente predita em $20 \%$ e $4 \%$ dos tratamentos, respectivamente, quando se utilizou valores críticos de concentração de $\mathrm{N}$ e leitura SPAD (Figura 2). Estes resultados indicam que a 


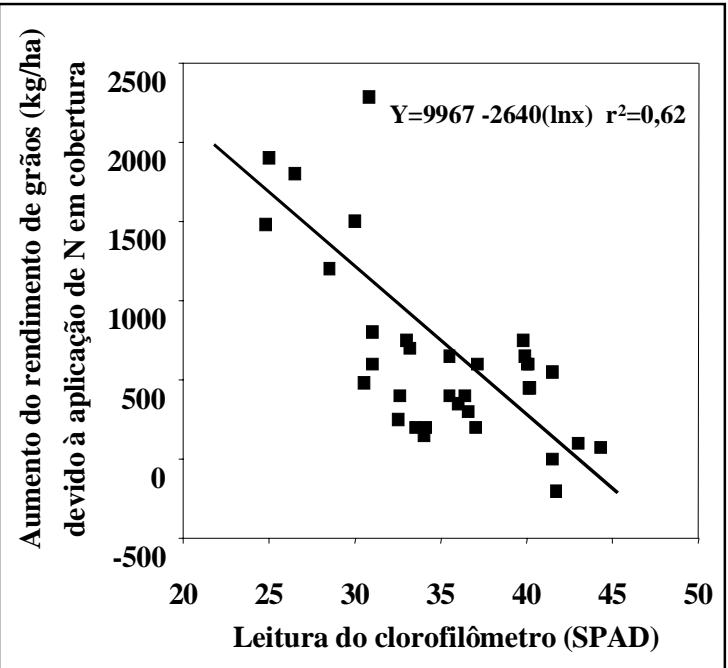

Figura 1 - Relação entre aumento do rendimento de grãos de arroz e leituras SPAD-502 nos estádios de iniciação da pré-panícula e diferenciação da panícula, em três locais dos Estados Unidos da América. Fonte: Adaptado de Turner \& Jund, 1991.

leitura SPAD é melhor parâmetro para predizer a necessidade de $\mathrm{N}$ do que o teor de $\mathrm{N}$. Neste estádio, o valor da leitura SPAD correspondente ao nível crítico foi de 41 . Na folha bandeira de trigo, os valores de leitura SPAD obtidos por outros pesquisadores situaram-se ao redor deste valor, 42 (FOLLET $\boldsymbol{e} t$ al., 1992) ou entre 37 e 42 (REEVES et al., 1993). No entanto, BREDEMEIER (1999) não constatou correlação entre leitura do clorofilômetro e resposta do rendimento de grãos de trigo no estádio Haun 5.1 (Figura 3A). A falta de associação foi atribuída principalmente à pequena amplitude entre as leituras máxima e mínima obtidas a campo. Porém, na cultura da aveia, também no estádio Haun 5.1, este autor constatou correlação positiva entre rendimento de grãos e nível de aplicação de $\mathrm{N}$ em cobertura (Figura 3B).

$\mathrm{Na}$ cultura do milho estão sendo estudadas as associações entre leitura do medidor de clorofila e rendimento de grãos. PIEKIELEK \& FOX (1992) reportaram ao fato de que as leituras no medidor de clorofila na planta no estádio de seis folhas poderiam predizer a resposta do rendimento de grãos à aplicação de $\mathrm{N}$ em cobertura. No entanto, WASKOM et al. (1996) não observaram correlação entre leituras do medidor de clorofila neste estádio com rendimento de grãos. Já no estádio de dez folhas, WOOD et al. (1992) verificaram que tanto o teor de N na planta como as leituras do teor de clorofila com o medidor portátil correlacionaram-se positivamente com rendimento de grãos. Medições realizadas em estádios de desenvolvimento mais tardios,
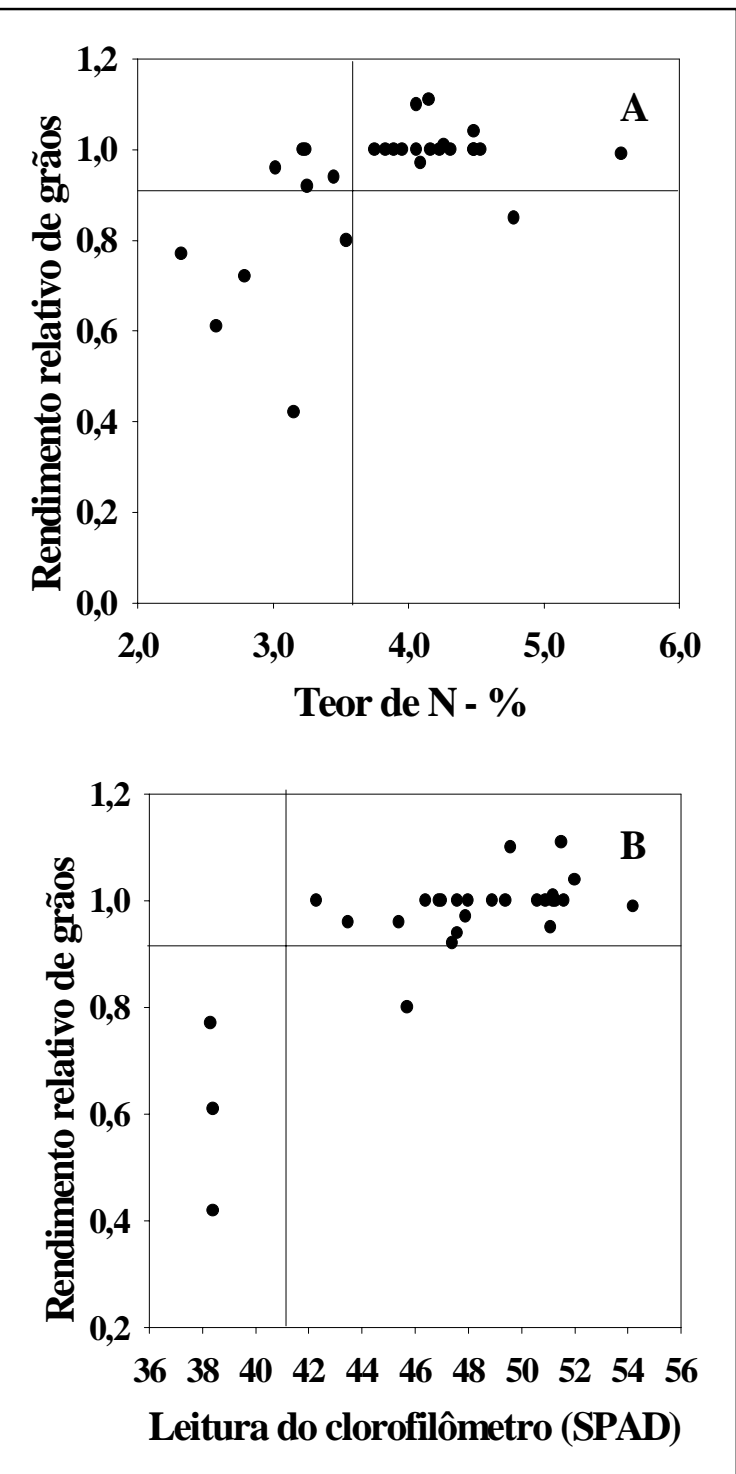

Figura 2 - Rendimento de grãos relativo de trigo em função do teor de N (A) e leitura SPAD (B), no estádio Feeke's 5, em três locais dos Estados Unidos da América. Fonte adaptado de Fox et al., 1994.

como floração e de grãos em estado de massa, predizeram melhor o rendimento de grãos (SUNDERMAN $\boldsymbol{e t}$ al., 1997, BLACKMER \& SCHEPERS, 1995).

No estádio do espigamento da cultura do milho, ARGENTA et al. (1999) desenvolveram três experimentos para determinar o nível adequado de $\mathrm{N}$. O primeiro ensaio foi implantado com o objetivo de determinar o valor adequado de $\mathrm{N}$ no espigamento e os outros dois foram realizados para determinar parâmetros de comparação com os valores obtidos no primeiro experimento (Figura 4). Através da derivação da equação da Figura 4A (Experimento I), foi determinado que o ponto de máxima leitura 


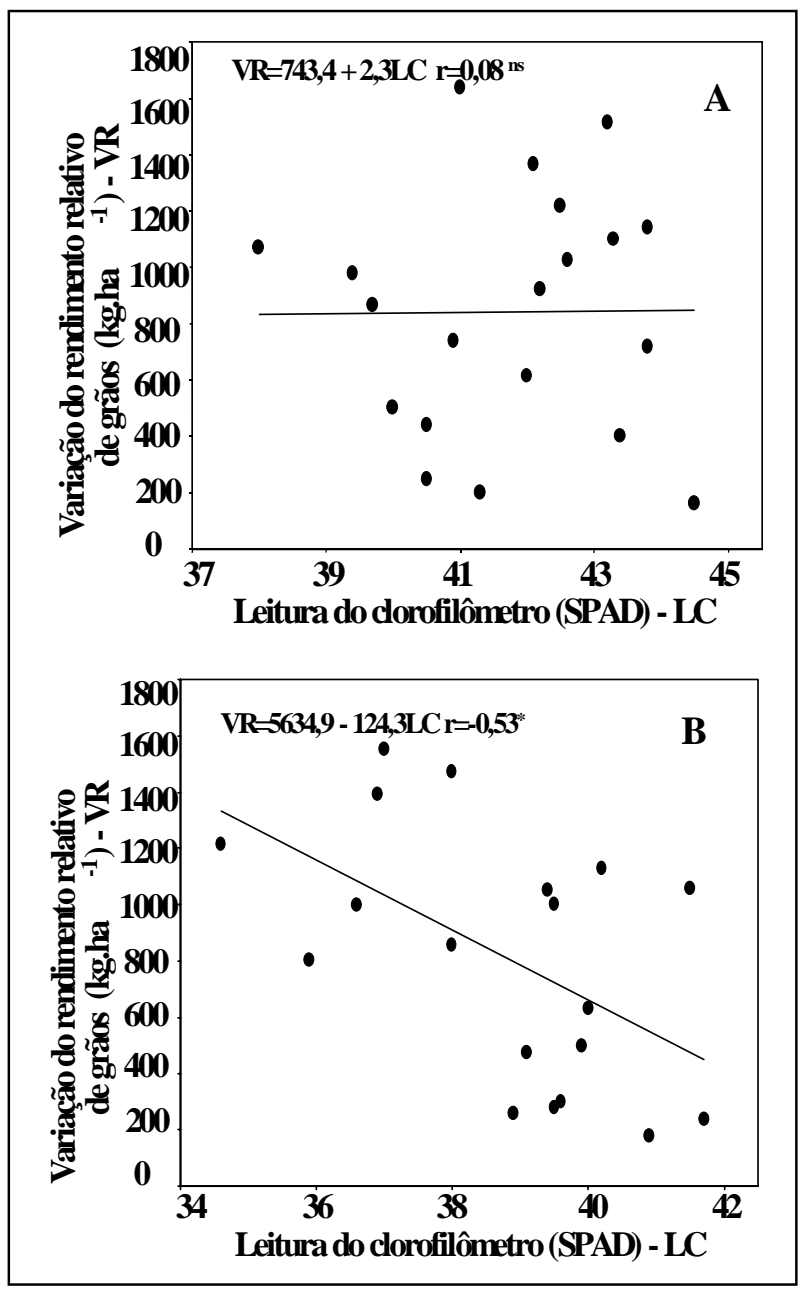

Figura 3 - Variação do rendimento de grãos de trigo (A) e aveia (B) com aplicação de $80 \mathrm{~kg} /$ ha de $\mathrm{N}$ em cobertura em função de leitura SPAD, no estádio Haun 5.1. EEA/UFRGS, Eldorado do Sul, RS, 1998.

Fonte: Adaptado de Bredemeier, 1999.

SPAD foi de 60,0. Adicionando-se a este valor o desvio padrão médio da leitura $\operatorname{SPAD}(2,0)$ determinou-se que o valor adequado de $\mathrm{N}$ situou-se na faixa SPAD de $60,0 \pm 2$. Ao se traçarem duas linhas paralelas ao eixo do $\mathrm{X}$ nos pontos correspondentes ao valor adequado de $\mathrm{N}$ determinado, observa-se que a maioria dos pontos médios localizou-se entre as duas linhas (Figura 4A). O mesmo pode ser constatado na figura 4B (Experimento I). Isto evidencia que $\mathrm{O}$ valor de leitura SPAD $60,0 \pm 2$ pode ser considerado como adequado indicador do nível adequado de $\mathrm{N}$ na planta de milho no estádio de espigamento. Valor similar de leitura SPAD também foi obtido neste estádio por SUNDERMAN et al. (1997).

A faixa de nível adequado de $\mathrm{N}$ determinada para o estádio de espigamento do milho foi validada em outros dois experimentos (Experimento
II e III) realizados no mesmo ano agrícola e local. Nestes ensaios, nenhum dos pontos médios localizou-se dentro da faixa correspondente ao nível adequado no Experimento I (Figuras 4C e 4D). O rendimento máximo de grãos nos Experimentos II e III foi de 9,4 e 10t/ha, respectivamente, sendo $22 \mathrm{e}$ $17 \%$ inferiores ao rendimento de grãos obtido no Experimento I, nos tratamentos em que os valores SPAD situaram-se na faixa considerada adequada.

$\mathrm{Na}$ cultura do milho, os resultados evidenciaram correlação somente nos estádios de desenvolvimento mais tardios. No entanto, o diagnóstico do nível adequado de $\mathrm{N}$ em estádios tardios de desenvolvimento da planta de milho não serve para correção deste nutriente ainda na estação de crescimento da cultura, pois o rendimento de grãos já estaria definido.

A baixa correlação obtida entre leitura SPAD e rendimento de grãos de milho, nos estádios iniciais de desenvolvimento, pode estar associada à metodologia adotada, que segue a utilizada nas culturas de arroz e trigo. Através desta metodologia, cria-se variabilidade de níveis de $\mathrm{N}$ através da aplicação de diferentes doses. Após gerada a variabilidade, não se aplica mais N. No entanto, é possível que a metodologia adotada em arroz e trigo não seja a ideal para o milho. Diferentemente destas culturas, o milho possui vários estádios de definição do rendimento de grãos. Assim, no estádio de 3 a 4 folhas completamente desenvolvidas ocorre a definição do número de fileiras da espiga (SCHREIBER $\boldsymbol{e t}$ al., 1988); nos estádios de 7-8 folhas e de 11-12 folhas são definidos, respectivamente, o número de óvulos nas fileiras e o tamanho da espiga (HANWAY, 1963); e no estádio correspondente a duas semanas antes a três semanas após a floração é determinada a quantidade de grãos formados (EARLEY et al., 1967). Portanto, a deficiência de $\mathrm{N}$ em qualquer um destes estádios poderá interferir no rendimento de grãos e, consequentemente, na correlação entre rendimento de grãos e leitura do medidor de clorofila. Assim, dependendo da situação, as plantas em um determinado estádio poderão estar bem nutridas com N. Porém, no decorrer do desenvolvimento da cultura, como não há mais aplicação de N, elas poderão apresentar deficiência deste nutriente e, consequentemente, ajustarem-se a esta situação através da redução da produção de grãos.

Neste sentido, para se obter melhores correlações na cultura do milho entre leituras com medidor de clorofila e rendimento de grãos nos estádios iniciais de desenvolvimento, faz-se necessário adotar-se metodologia adequada ao estádio de desenvolvimento da cultura. Para a determinação de níveis 


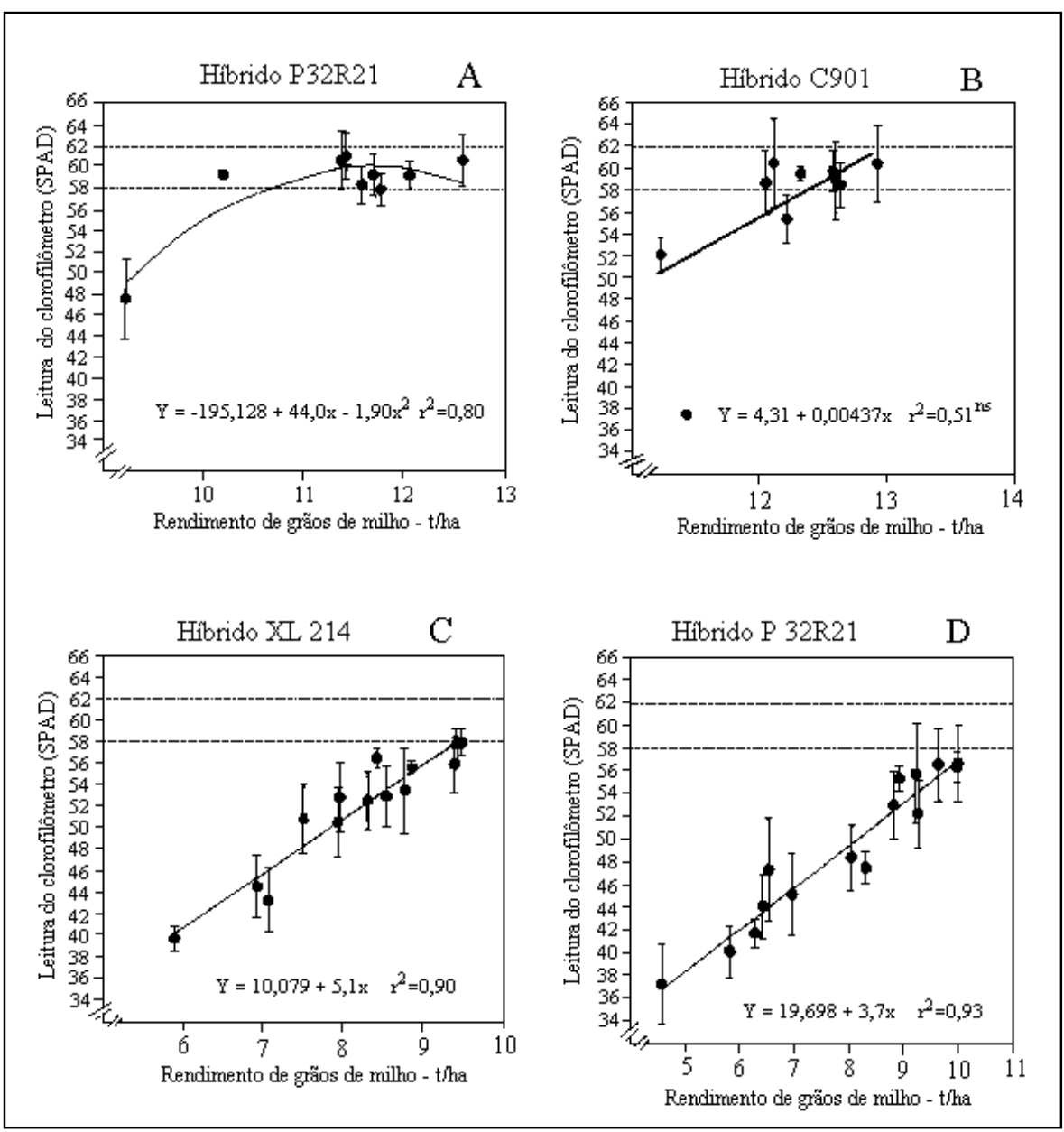

Figura 4 - Relação entre leitura do teor relativo de clorofila na primeira folha abaixo da espiga de milho (folha índice) no espigamento, avaliada através do medidor portátil de clorofila, e rendimento de grãos, nos Experimentos I, (A) e (B), II (C) e III (D). Eldorado do Sul, RS, 1998/99. Barras verticais representam desvio padrão da média. NS=não significativo, a 5\% de probabilidade. Fonte: Argenta et al., 1999.

adequados de $\mathrm{N}$, a planta de milho deverá estar bem nutrida com este nutriente durante todo o ciclo vegetativo. A variabilidade do teor de $\mathrm{N}$ na planta deverá ser gerada em todos os estádios em que se deseja determinar o seu nível crítico.

\section{LIMITAÇÕES E PERSPECTIVAS DA UTILIZAÇÃO DO TEOR DE CLOROFILA NA FOLHA COMO PARÂMETRO INDICADOR PARA O MANEJO DE N EM CEREAIS}

A utilização do teor de clorofila, determinado através do medidor portátil de clorofila, apresenta limitações como parâmetro indicador para o manejo de $\mathrm{N}$ em cereais tais como: pouca amplitude das leituras SPAD; outros fatores podem estar afetando a síntese de clorofila, além da disponibilidade de $\mathrm{N}$ no solo; baixa precisão quando os teores de $\mathrm{N}$ na planta são altos; pouca precisão para determinar a quantidade a se aplicar de $\mathrm{N}$ e, especificamente em milho, baixa correlação da leitura SPAD com rendimento de grãos verificada nos estádios iniciais de desenvolvimento.

Para corrigir ou minimizar as limitações citadas acima, algumas estratégias estão sendo recomendadas. Uma delas é a utilização de faixas de referência em que a cultura é adequadamente adubada no mesmo campo e com a mesma cultivar. Quando o percentual relativo de clorofila for abaixo de $95 \%$ da referência, sugere-se a aplicação adicional de fertilizante nitrogenado (VARVEL $\boldsymbol{e t}$ al., 1997; WASKOM et al., 1996; BLACKMER \& SCHEPERS, 1995).

Ainda que a utilização de uma faixa de referência funcione bem na prática para corrigir o efeito de outros fatores na concentração de clorofila, ela requer amostragem extensiva. $\mathrm{O}$ uso de uma faixa de referência poderia ser evitado se fossem considerados alguns fatores como, por exemplo, a espessura da folha (CHAPMAN \& BARRETO, 1997). PENG et al. (1993) concluíram que, em arroz, os efeitos varietais e de estádio de desenvolvimento nas leituras do medidor de clorofila podem ser removidos simplesmente pela divisão do valor da leitura pelo peso específico da folha (peso seco/área foliar), uma vez que este parâmetro está associado à espessura da folha (PETTIGREW $\boldsymbol{e} t$ al., 1993). Em milho, CHAPMAN \& BARRETO (1997) também verificaram aumento no coeficiente de determinação (de 0,81 para 0,97 ) quando dividiram os valores das leituras no medidor pelo peso específico da folha. Além do uso deste parâmetro, outras formas de correção podem ser obtidas pela utilização da área foliar e da massa seca da planta. 
Apesar da existência de algumas limitações, existem outras perspectivas de uso do teor relativo de clorofila, além da sua utilização no manejo de $\mathrm{N}$ nos cereais, como: integração de medidas de solo (teor de matéria orgânica, $\mathrm{N}$ disponível) com as leituras SPAD para refinar as recomendações de adubação nitrogenada (WASKOM et al., 1996); utilização nos modelos de simulação de crescimento (PENG et al., 1993) ou de monitoramento de mudanças no grau de esverdeamento da folha (DWYER et al., 1991) e verificação do nível de $\mathrm{N}$ em comunidade de plantas através de sensoreamento remoto (BAUSCH \& DUKE, 1996).

Outras vantagens da utilização deste método de avaliação do nível de $\mathrm{N}$ nas plantas são: a leitura pode ser realizada em poucos minutos, possibilitando rápido diagnóstico da situação da lavoura; o aparelho tem custos mínimos de manutenção, ao contrário de outros testes que exigem a compra sistemática de produtos químicos (PIEKIELEK \& FOX, 1992); não existe a necessidade de envio de amostras para laboratório, com economia de tempo e dinheiro, e o agricultor pode realizar quantas amostras desejar, sem destruição de folhas (MALAVOLTA et al., 1997).

A maior limitação da utilização do teor de clorofila na folha como indicador do nível de $\mathrm{N}$ em cereais é que ele não prediz quanto de adubação nitrogenada suplementar deverá ser aplicada (WASKOM et al., 1996; SUNDERMAN et al., 1997). Por outro lado, os indicadores de solo não predizem com segurança quando este nutriente deverá ser aplicado (SCHRÖDER et al., 2000). Assim, fica evidente a necessidade da integração de indicadores do nível de $\mathrm{N}$ (solo e planta) para aumentar a precisão da recomendação de adubação nitrogenada em cereais.

\section{CONCLUSÕES}

O teor relativo de clorofila na folha, avaliado pelo medidor portátil de clorofila, evidencia ser um bom parâmetro indicador do nível de nitrogênio em cereais.

Além da sua utilização no manejo de $\mathrm{N}$ nos cereais, a determinação do teor de clorofila com clorofilômetro apresenta outras possibilidades de uso como na integração das medidas de solo com as leituras SPAD, na utilização em modelos de simulação de crescimento ou de monitoramento de mudanças no grau de esverdeamento da folha e na verificação do nível de $\mathrm{N}$ na comunidade de plantas através de sensoreamento remoto.

Por se tratar de uma técnica nova, apresenta limitações, tais como: pouca amplitude entre as leituras, a influência de outros fatores sobre as leituras além do $\mathrm{N}$ e, especificamente para o milho, apresentação de baixa correlação com rendimento de grãos nos estádios iniciais de desenvolvimento da planta.

A utilização do teor de clorofila na folha como indicador do nível de $\mathrm{N}$ em cereais não prediz quanto de adubação nitrogenada suplementar deverá ser aplicada. Portanto, a sua utilização no manejo da adubação nitrogenada em cereais é mais benéfica quando associada a um indicador de solo, que por sua vez, não prediz com segurança quando este nutriente deve ser aplicado.

\section{REFERÊNCIAS BIBLIOGRÁFICAS}

ARGENTA, G., SILVA, P.R.F., BORTOLINI, C.G., et al. Teor de clorofila na folha como indicador do nível de nitrogênio na planta de milho no espigamento. In: REUNIÃO TÉCNICA CATARINENSE: MILHO \& FEIJÃO, 2, 1999, Lages, Resumos... Lages : UDESC/EPAGRI, 1999. p.44-49.

BAUSCH, W.C., DUKE, H.R. Remote sensing of plant nitrogen status in corn. Transactions of the ASAE, St. Joseph, v.39, n.5, p.1869-1875, 1996.

BLACKMER, T.M., SCHEPERS, J.S. Techniques for monitoring crop nitrogen status in corn. Communications in Soil Science and Plant Analysis, New York, v.25, n.9/10, p.1791-1800, 1995 .

BREDEMEIER, C. Predição da necessidade de nitrogênio em cobertura em trigo e aveia. Porto Alegre, 1999. 101p. Dissertação (Mestrado em Agronomia, Fitotecnia) Programa de Pós-graduação em Agronomia, Universidade Federal do Rio Grande do Sul, 1999.

CHAPMAN, S.C., BARRETO, H.J. Using a chlorophyll meter to estimate specific leaf nitrogen of tropical maize during vegetative growth. Agronomy Journal, Madison, v.89, n.4, p.557-562, 1997.

COMISSÃO DE FERTILIDADE DO SOLO - RS/SC Recomendações de adubação e de calagem para os estados do Rio Grande do Sul e de Santa Catarina. Passo Fundo: SBCS-Núcleo Regional Sul, 1995. 223p.

DWYER, L.M., ANDERSON, A.M., MA, B.L., $\boldsymbol{e t} \boldsymbol{a l}$ Quantifying the nonlinearity in chlorophyll meter response to corn leaf nitrogen concentration. Canadian Journal of Plant Science, Ottawa, v.75, n.1, p.179-182, 1995.

DWYER, L.M., TOLLENAAR, M., HOUWING, L. A nondestructive method to monitor leaf greenness in corn. Canadian Journal of Plant Science, Ottawa, v.71, n.3, p.505-509, 1991.

EARLEY, E.B., MCIIRATH, W.O., SEIF, R.D., et al. Effects of shade applied at different stages of plant development on corn (Zea mays L.) production. Crop Science, Madison, v.7, n.1, p.151-156, 1967.

EDMISTEN, K.L., WOOD, C.W., REEVES, D.W., $\boldsymbol{e t} \boldsymbol{a l}$. Determination of cotton nitrogen status with a hand-held chlorophyll meter in Alabama and Missouri. National Cotton Councill of America, Madison, v.3, n.3, p.1101-1102, 1992. 
FOLLETT, R.H., FOLLETT, R.F., HALVORSON, A.D. Use of a chlorophyll meter to evaluate the nitrogen status of dryland winter wheat. Communications in Soil Science and Plant Analysis, New York, v.23, n.7/8, p.687-697, 1992.

FOX, R.H., PIEKIELEK, W.P., MACNEAL, K.M. Using a chlorophyll meter to predict nitrogen fertilizer needs of winter wheat. Communications in Soil Science and Plant Analysis, New York, v.25, n.3/4, p.171-181, 1994.

FRAISSE, C.W. Agricultura de precisão - oportunidades e desafios. Curitiba : UFPR, 28 de maio, 1998. Palestra proferida na Mostra Sobre Agricultura de Precisão (CD ROM 9p.)

HANWAY, J.J. Growth stages of corn (Zea mays L.) Agronomy Journal, Madison, v.55, n.5, p.487-491, 1963.

HARTZ, T.K., LESTRANGE, M., MAY, D.M. Nitrogen requirements of drip-irrigated peppers. HortScience, Alexandria, v.28, n.10, p.1097-1099, 1993.

HENDRY, G.A. Plant pigments. In: LEA. P.J., LEEGOOD, R.C Plant biochemistry and molecular biology. Great Britain: Bookcraft, 1993. p.181-196.

KAAKEH, W., PFEIFFER, D.G., MARINI, R.P. Combined effects of spirea aphid (homoptera: Aphidae) and nitrogen fertilization on net photosynthesis, total chlorophyll content, and greenness of apple leaves. Journal of Economic Entomology, Lanham, v.85, n.5, p.939-946, 1992.

LEMAIRE, G., GASTAL, F.N. N uptake and distribution in plant canopies. In: LEMAIRE, G. (Ed.). Diagnosis of the nitrogen status in crops. Berlin : Springer, 1997. p.1-56.

MAlAVOlTA, E., VITTI, G.C., OLIVEIRA, S.A. Avaliação do estado nutricional das plantas: princípios e aplicações. Piracicaba : POTAFÓS, 1997. 319p.

MARQUARD, R.D., TIPTON, J.L. Relationship between extractable chlorophyll and an in situ method to estimate leaf greenness. HortScience, Alexandria, v.22, n.6, p.1327, 1987.

MINOLTA CAMERA Co., Ltda. Manual for chlorophyll meter SPAD 502. Osaka : Minolta, Radiometric Instruments divisions. 1989. 22p.

PENG, S., GARCIA, F.V., LAZA, R.C., et al. Adjustment for specific leaf weigth improves chlorophyll meter's estimate of rice leaf nitrogen concentration. Agronomy Journal, Madison, v.85, n.5, p.987-990, 1993

PETTIGREW, W.T., HEITHOLT, J.J., VAUGHN, K.C. Gas exchange differences and comparative anatomy among cotton leaf-type isolines. Crop Science, Madison, v.33, n.6, p.12951299, 1993.

PIEKIELEK, W.P., FOX, R.H. Use of a chlorophyll meter to predict sidedress nitrogen requirements for maize. Agronomy Journal, Madison, v.84, n.1, p.59-65, 1992.

REEVES, D.W., MASK, P.L., WOOD, C.W. et al. Determination of wheat nitrogen status with a hand-held chlorophyll meter: influence of management practices. Journal of Plant Nutrition, New York, v.16, n.4, p.781-796, 1993.
SCHADCHINA, T.M., DMITRIEVA, V.V. Leaf chlorophyll content as a possible diagnostic mean for the evaluation of plant nitrogen uptake from the soil. Journal of Plant Nutrition, New York, v.18, p.1427-1437, 1995.

SCHREIBER, H.A, STANBERRY, C.O., TUCKER, H. Irrigation and nitrogen effects on sweet corn row number at various growth stages. Science, Washington, v.135, n.1, p.135-136, 1988.

SCHRÖDER, J.J., NEETESON, J.J., OENEMA, O., et al. Does the crop or the soil indicate how to save nitrogen in maize productio? Reviewing the state of the art. Field Crops Research, Amsterdam, v.66, n.1, p.151-164, 2000.

SIMS, J.T., VASILAS, B.L., GARTLEY, K.L., et al. Evaluation of soil and plant nitrogen tests for maize on manured soils of the Atlantic coast plain. Agronomy Journal, Madison, v.87, n.2, p.213-222, 1995.

SINCLAIR, T.R., MUCHOW, R.C. Effect of nitrogen supply on maize yield: I. Modeling physiological responses. Agronomy Journal, Madison, v.87, n.4, p.632-641, 1995.

SMEAL, D., ZHANG, H. Chlorophyll meter evaluation for nitrogen management in corn. Communications in Soil Science and Plant Analysis, New York, v.25, n.9/10, p.1495-1503, 1994.

STOKING, C.R., ONGUN, A. The intracellular distribuition of some metallic elements in leaves. American Journal of Botany, Columbus, v.49, n.3, p.284-289, 1962.

SUNDERMAN, H.D., PONTIUS, J.S., LAWLESS, J.R. Variability in leaf chlorophyll concentration among fullyfertilized corn hybrids. Communications in Soil Science and Plant Analysis, New York, v.28, n.19, p.1793-1803, 1997.

TENGA, A.Z., MARIE, B.A., ORMROD, D.P. Leaf greenness meter to assess ozone injury to tomato leaves HortScience, Alexandria, v.24, n.4, p.514, 1989.

TURNER, F.T., JUND, M.F. Chlorophyll meter to predict nitrogen topdress requeriment for semidwarf rice. Agronomy Journal, Madison, v.83, n.5, p.926-928, 1991.

VARVEL, G.E., SCHEPERS, J.S., FRANCIS, D.D. Ability for in-season correction of nitrogen deficiency in corn using chlorophyll meters. Soil Science Society of America Journal, Madison, v.61, n.4, p.1233-1239, 1997.

WASKOM, R.M., WESTFALL, D.G., SPELLMAN, D.E., $\boldsymbol{e} \boldsymbol{t} \boldsymbol{a l}$. Monitoring nitrogen status of corn with a portable chlorophyll meter. Communications in Soil Science and Plant Analysis, New York, v.27, n.3, p.545-560, 1996.

WILSON, W.S., MOORE, K.L., ROCHFORD, AD., et al. Fertilizer nitrogen addition to winter wheat crops in England: comparison of farm practices with recommendations allowing for soil nitrogen suply. Journal of Agricultural Science, Cambridge, v.127, n.1, p.11-22, 1996.

WOOD, C.W., REEVES, D.W., DUFFIELD, R.R., et al. Field chlorophyll measurements for evaluation of corn nitrogen status. Journal of Plant Nutrition, New York, v.15, n.4, p.487-500, 1992. 